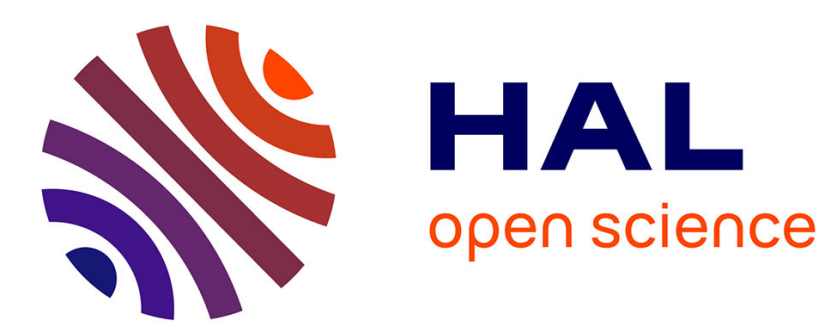

\title{
Comparison of Emotional Responses in Monkeys With Rhinal Cortex or Amygdala Lesions
}

\author{
Martine Meunier, Jocelyne Bachevalier
}

\section{To cite this version:}

Martine Meunier, Jocelyne Bachevalier. Comparison of Emotional Responses in Monkeys With Rhinal Cortex or Amygdala Lesions. Emotion, 2002, 2, pp.147-161. hal-00000182

\section{HAL Id: hal-00000182 \\ https://hal.science/hal-00000182}

Submitted on 11 Feb 2003

HAL is a multi-disciplinary open access archive for the deposit and dissemination of scientific research documents, whether they are published or not. The documents may come from teaching and research institutions in France or abroad, or from public or private research centers.
L'archive ouverte pluridisciplinaire HAL, est destinée au dépôt et à la diffusion de documents scientifiques de niveau recherche, publiés ou non, émanant des établissements d'enseignement et de recherche français ou étrangers, des laboratoires publics ou privés. 


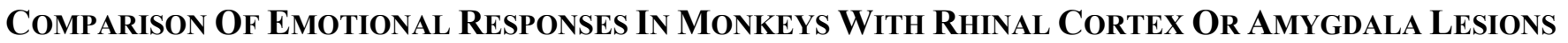

\author{
Martine Meunier (Institut des Sciences Cognitives, CNRS, Bron, France) and \\ Jocelyne Bachevalier (University of Texas Health Science Center, Houston, TX, USA)
}

Emotion 2002, Vol. 2, 147-161

Correspondence to: Jocelyne Bachevalier, Department of Neurobiology and Anatomy, University of Texas Health Science Center-Houston, 6431 Fannin, Houston, TX 77030, USA. Phone: 713-500-5626, Fax: 713-500-0621, Email: Jocelvne.Bachevalier@uth.tmc.edu

Four emotionally arousing stimuli were used to probe the behavior of monkeys with bilateral ablations of the entorhinal and perirhinal cortex. The animals' behavioral changes were then contrasted with those observed earlier (Meunier et al., 1999) in monkeys with either neurotoxic or aspiration lesions of the neighboring amygdala. Rhinal cortex ablations yielded several subtle behavioral changes, but none of them resembled any of the disorders typically seen after amygdalectomies. The changes produced by rhinal damage took mainly the form of heightened defensiveness, and attenuated submission and approach responses, that is, just the opposite of some of the most distinctive symptoms following amygdala damage. These findings raise the possibility that the rhinal cortex and amygdala have distinct, interactive, functions in normal behavioral adaptation to affective stimuli.

\section{INTRODUCTION}

Conventional, aspiration or radiofrequency, lesions of the amygdala in monkeys have long been known to yield profound emotional disorders (Weiskrantz, 1956; Horel et al., 1975; Aggleton \& Passingham, 1981; Zola-Morgan et al., 1991; Kling \& Brothers, 1992), often designated as "Klüver-Bucy symptoms", in reference to the landmark description of the effects of temporal lobectomy in monkeys given by Klüver and Bucy (1939). Subsequently, it has been pointed out that conventional amygdala lesions lead to extensive indirect damage to adjacent medial temporal cortex by transecting fibers coursing through and nearby the amygdala (Murray, 1996). Hence, in a recent study, the emotional behavior of monkeys with neurotoxic lesions of the amygdala, which spare fibers of passage, was compared to that of monkeys with aspiration removals of the amygdala (Meunier et al., 1999). Both types of lesion led to the same pattern of changes, but differences did emerge in the magnitude of some symptoms. Among the major changes following amygdalectomy, reduction of fear was similar after both types of lesion. By contrast, aggression attenuation and submission enhancement were more clear-cut, and excessive manual and oral exploration of objects was more pervasive after aspiration removals than after neurotoxic lesions. These variations in the magnitude of the emotional changes suggested that indirect damage to medial temporal cortex, although not primarily responsible for the emotional disorders produced by conventional amygdalectomy in monkeys, might nonetheless aggravate them.

Amygdala aspiration interrupts non-amygdaloid fibers originating in the rhinal cortex (i.e. the entorhinal and perirhinal areas), temporal polar area TG, and inferior temporal area TE (Baxter et al., 1998; Goulet et al., 1998). Dysfunction of area TG and/or TE may aggravate the impact of amygdala damage on emotions given that Klüver-Bucylike symptoms such as lessened fear and aggression, and increased manual, oral, or olfactory exploration have occasionally been reported after extensive lesions or disconnection involving either of these two areas (Akert et al., 1961; Myers \& Swett, 1970; Meyer, 1972; Franzen \& Myers, 1973; Horel \& Misantone, 1974; Horel et al., 1975; Raleigh \& Steklis, 1981; Iwai et al., 1986; Kling et al., 1993). By contrast, the consequences of rhinal cortex lesions on emotions are unknown. Since even fiber-sparing amygdala lesions frequently invade some portion of this cortical region (due to neurotoxin spread; see Meunier et al., 1999; Emery et al., 2001; Kalin et al., 2001), it seemed necessary to assess to which extent, if any, extradamage to rhinal cortex might have influenced the behavior of amygdalectomized monkeys.

To this aim, monkeys with ablations of the rhinal cortex were submitted to the same protocol as that used previously to assess emotional changes following amygdala lesions (Meunier et al., 1999). The animals were exposed to four stimuli, two with a social component (an unfamiliar human and a conspecific stimulus) and two non-social stimuli (one positive and one negative). The expression of defense, aggression, submission, and approach behaviors were first evaluated relative to unoperated animals, and then contrasted with that recorded earlier after aspiration removals and neurotoxic lesions of the amygdala.

A preliminary report of this work has appeared elsewhere (Meunier et al., 1991).

\section{METHODS}

\section{Subjects}

The study was approved by the NIMH Animal Care and Use Committee. The subjects were six adult rhesus monkeys (Macaca mulatta), three male and three female, weighing 3.5 to $4.5 \mathrm{~kg}$ at the time of surgery. They were housed individually in rooms with automatically regulated lighting ( $12 \mathrm{~h}$ light/dark cycle), and were maintained on a diet of monkey chow (no. 5038, PMI Feeds, St Louis, MO) supplemented with fruit. Food was given ad libitum once a day after completion of the behavioral testing; water was always available. These six animals were given selective aspiration lesions of the rhinal cortex (Rh), including both the entorhinal and perirhinal cortex, and were compared to 12 male rhesus monkeys reported in Meunier et al. (1999). The 12 comparison monkeys included six unoperated controls $(\mathrm{N})$, and six animals with virtually total damage to the amygdala: three with aspiration removals $\left(\mathrm{A}_{\mathrm{ASP}}\right)$ and three with neurotoxic lesions $\left(\mathrm{A}_{\mathrm{IBOc}}\right)$. All six monkeys in group $\mathrm{Rh}$ had previously been subjects in a memory study (Meunier et al., 1993), as had monkeys in the three comparison groups (see Meunier et al., 1999).

Surgery

The surgical procedure has been extensively described in the memory study involving the same subjects (Meunier et al., 1993). 

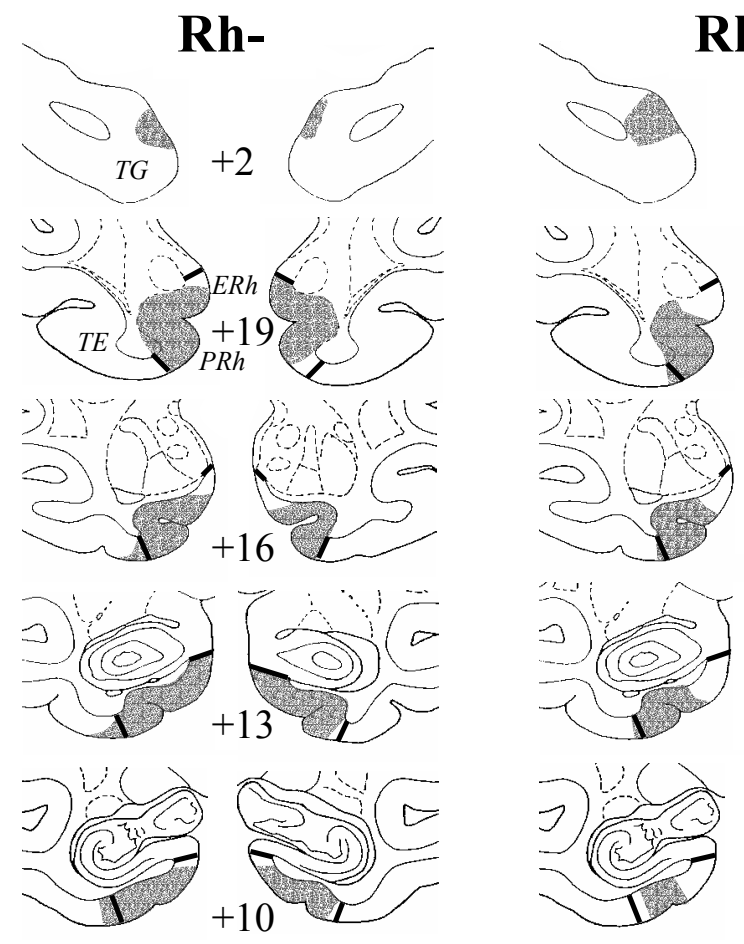

Rh-3
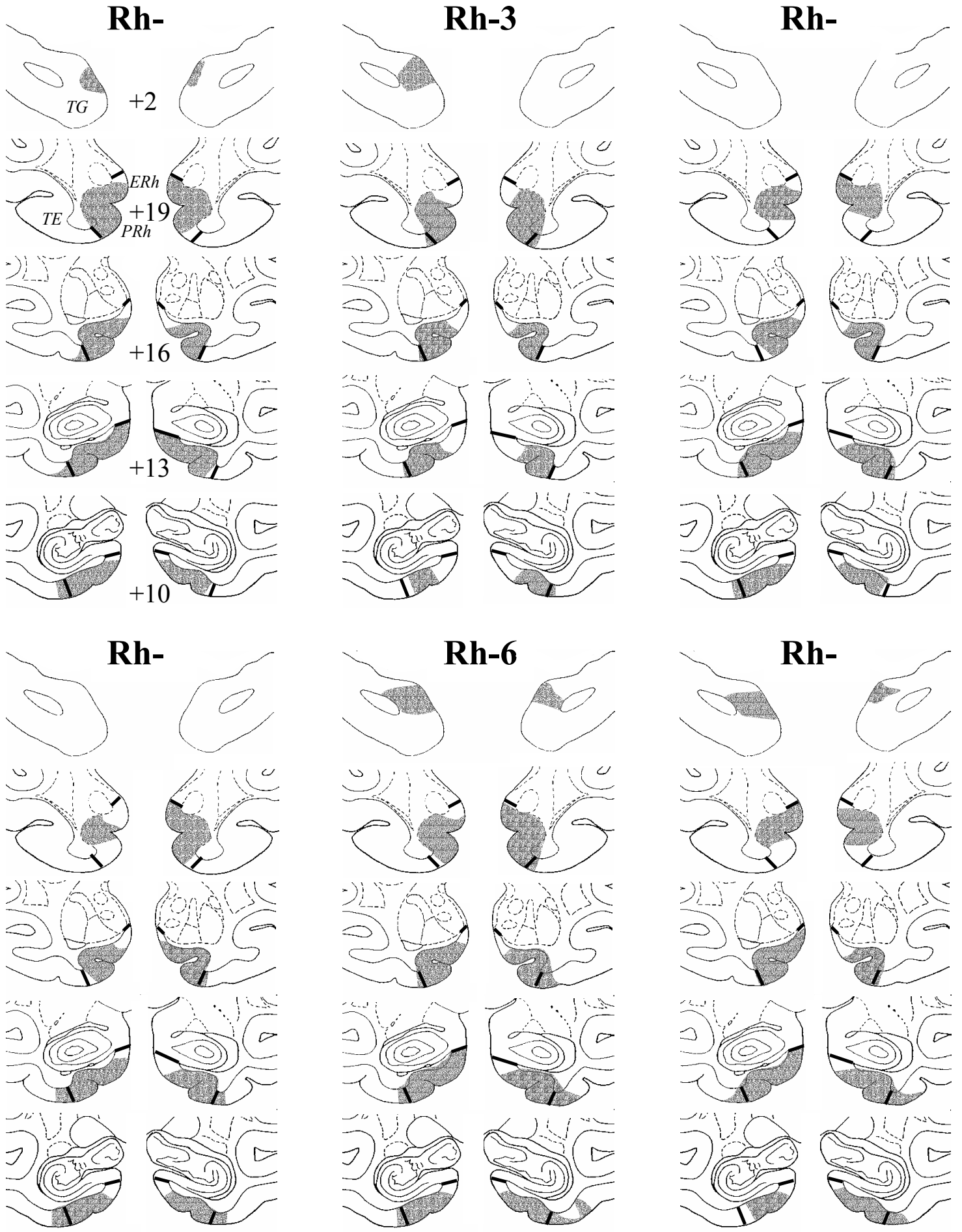

Figure 1. Estimated location and extent of the aspiration lesions of the rhinal cortex (shaded areas) for each of the six animals included in the present study (labeled Rh-2 to 7 to maintain the same case numbers as in previous memory studies involving the same subjects; Meunier et al., 1993, 1996). The lesions are plotted on coronal sections taken through the medial temporal lobes of a normal rhesus monkey brain. Numerals refer to approximate stereotaxic levels of the sections. The thick lines indicate the approximate location of the medial and lateral boundaries of the rhinal cortex. ERh, entorhinal area; PRh, perirhinal area; TE, inferior temporal area; TG, temporal polar area. 
Briefly, five animals received the rhinal cortex ablation in a single bilateral stage, whereas the remaining monkey received it in two unilateral stages separated by a 2 -week interval. In all cases, the zygomatic arch was removed, as well as the bone covering the frontal and temporal lobes. The rostral portion of the entorhinal (area 28) and perirhinal (areas 35 and 36) cortex was ablated first, after gentle elevation of the frontal lobe to expose the medial temporal pole. Then, the monkey's head was tilted at an angle of $120^{\circ}$ from the upright position, the posterior temporal lobe was slightly lifted, and the caudal half of the rhinal cortical areas was removed. The tissue was aspirated via a small-gauge sucker with the aid of an operating microscope. The ablation included both banks of the rhinal sulcus, together with 2 to 5 $\mathrm{mm}$ of cortex medial to it, and $2 \mathrm{~mm}$ of cortex lateral to it.

\section{Lesion assessment}

The location and extent of the rhinal cortex lesions have been detailed in Meunier et al. (1993), and the estimated volumes of direct damage to the entorhinal, perirhinal, parahippocampal (TH/TF), and TE areas have been provided for each animal by Meunier et al. (1996). The animals included in the present study correspond to cases $\mathrm{Rh} 2$ to 7 in both earlier studies (case Rh-1 did not undergo emotional testing). As illustrated in Fig. 1, the entorhinal and perirhinal lesions sustained by these six monkeys were bilaterally symmetrical. The volume of damage averaged $78 \%$ (range, $68-87 \%$ ) of the total extent of rhinal cortex. This included an average of $70 \%$ (range, $42-82 \%$ ) of the entorhinal cortex and $86 \%$ (range, $77-97 \%$ ) of the perirhinal cortex. Sparing consistently involved the most medial portion of entorhinal cortex underlying the caudal half of the amygdala, together with the rostrolateral tip of perirhinal cortex bordering the temporal pole. In all cases, the lesions slightly encroached on the parahippocampal cortex, caudally (average, $10 \%$ of the total volume; range, 3-13\%), but damage to medially adjacent area TE was minimal (average, 3\%; range: $1-7 \%$ ), as was the involvement of temporal polar area TG, rostrally (average, $2 \%$; range: $0-4 \%$ ). The amygdala was always left intact.

The lesions sustained by amygdalectomized animals have also been described elsewhere (Murray et al., 1996, Málková et al., 1997; Meunier et al., 1999). For comparison, all three cases in group $\mathrm{A}_{\mathrm{ASP}}$ had extensive ablations of the amygdala (average, 95\%; range, 89$98 \%$ ), as well as a variable amount of direct bilateral damage to the entorhinal cortex (average, 22\%; range, 1-51\%). The other adjacent temporal cortical areas sustained indirect damage in these three cases due to transection of fibers coursing through and around the amygdala. Group $\mathrm{A}_{\mathrm{IBOc}}$ showed a cell loss encompassing virtually all the amygdala (average, 97\%; range, 94-99\%), and encroaching substantially, albeit mainly unilaterally in two of the three cases, onto entorhinal cortex (average, 35\%; range, 25-55\%). Direct damage to perirhinal cortex was negligible $(\leq 3.5 \%)$ in both groups of amygdalectomized animals.

\section{Evaluation of emotional responses}

The apparatus, stimuli, recording procedure, and scoring method were identical to those described by Meunier et al. (1999). Testing was conducted in a Wisconsin General Testing Apparatus (WGTA) which inner and outer screens were raised to allow video-recording of the animal's behavior. As illustrated in Fig. 2, each daily session lasted either 9 or $10 \mathrm{~min}$, of which four samples of the animal's behavior lasting either 1 or $2 \mathrm{~min}$ each were video-recorded. A single stimulus was presented per session during the third recorded sample for $20 \mathrm{sec}$, or $4 \times 20 \mathrm{sec}$. A set of four stimuli was used, including an unfamiliar human, a conspecific stimulus, a negative item, and a positive item.

The unfamiliar human (Human Face) was the experimenter sitting in a chair approximately $80 \mathrm{~cm}$ from the animal's cage, and wearing a white laboratory coat and a rubber face mask. The experimenter avoided eye contact during the first $10 \mathrm{sec}$ of the presentation, but looked straight at the animal's face during the last $10 \mathrm{sec}$. The conspecific stimulus (Monkey Head) was a taxidermic monkey head attached to a $50-\mathrm{cm}$ wooden rod. This stimulus was first placed gently on the testing area of the WGTA for $10 \mathrm{sec}$, and then thrust towards the animal's cage and held there for the remaining $10 \mathrm{sec}$. The negative item (Snake) was an $80-\mathrm{cm}$ toy rubber snake (sociallyreared normal monkeys having a well-known tendency to fear snakes, real and toy alike; see e.g. Mineka \& Cook, 1988). This stimulus was introduced suddenly on the testing area and held there for $20 \mathrm{sec}$. Finally, the positive item (Object) was a large object concealing a 300-mg banana pellet (P.J. Noyes, Lancaster, $\mathrm{NH}$ ) or a half-peanut (all animals in this study having previously been trained to displace objects to obtain food rewards). A test tray equipped with three food wells was first positioned inside the WGTA. Then, the reward was placed in the central well and covered by the stimulus. There were four consecutive 20 -sec presentations of the Object per daily session. On the fourth presentation, the reward was omitted, to evaluate the monkey's reactions to an unexpected and presumably frustrating event. The inner, opaque screen of the WGTA was lowered before each presentation to mask the baiting (or lack thereof) of the well. Except for Human Face presentation, the experimenter remained out of the animal's view during the entire duration of each session by standing to one side of the WGTA. The four stimuli were each presented once a week for three consecutive weeks, appearing in a different sequence each week, but in the same overall sequence for all subjects.

\section{Human Face, Monkev Head, Snake}

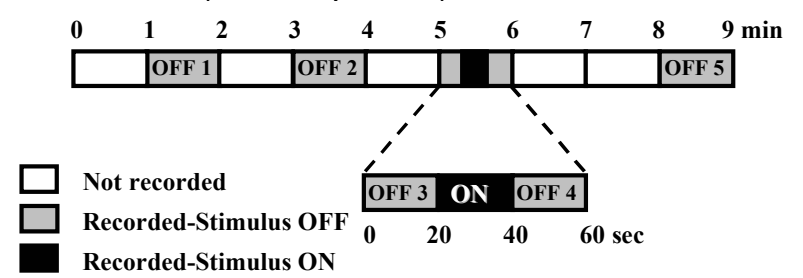

Object

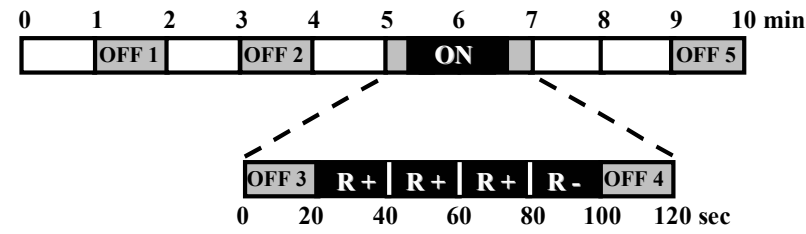

Figure 2. Daily video-recording session. Each session consisted of a fixed sequence of non-recorded and recorded periods. The animal's general behavior was sampled before and after stimulus presentation for a total of three 1-min segments (OFF 1, 2, and 5) and two 20-sec segments (OFF 3, and 4). A single stimulus was presented per session $(O N)$ during the third recorded period. For the two "social" stimuli (Human Face and Monkey Head), and the negative item (Snake), there was one single 20-sec presentation per session (top). For the positive item (Object), there were four consecutive 20-sec presentations per session (bottom); a food reward was hidden under the stimulus during the first three presentations $(R+)$, but not during the fourth (R-). 
Table 1. Behavioral activities measured before and after (top) vs. during (bottom) stimulus presentation.

\begin{tabular}{|c|c|}
\hline \multicolumn{2}{|c|}{ BEHAVIORS IN ABSENCE OF A STIMULUS $(r=0.99)$} \\
\hline - Passive (no body motion) & - Oral exploration \\
\hline - Move (unspecific motor activity) & - Locomotor Stereotypies (e.g. circling) \\
\hline - Manual exploration & - Self-directed Activities (e.g. scratching) \\
\hline
\end{tabular}

\section{BEHAVIORS DURING STIMULUS PRESENTATION}

MILD AGGRESSION $(r: N A)$

- Frown

- Ears Back

- Yawn

HIGH AGGRESSION $(r=0.93)$

- Head or Body Lunge

- Cage Shake

- Mouth Threat

- Striking Attack

- Biting Attack

APPROACH $(r=0.98)$

- Look At

- Move Toward

- Touch

- Mouth (with or without Touch)

- Smell

- Take and Eat Reward (hidden underneath the Object)

\author{
SUBMISSION $(r=0.94)$ \\ - Lip Smack \\ - Grimace \\ - Hindquarter Presentation
}

DEFENSE $(r=0.91)$

- Freezing (motionless for at least $3 \mathrm{sec}$ )

- Startle

- Eye or Head Aversion

- Piloerection

- Move Away

OTHER BEHAVIORS [NOT DIRECTED TOWARDS THE STIMULUS] $(r=0.80)$

- Manipulate (parts of cage or apparatus)

- Locomotor Stereotypies

- Self-Directed Activities

- Miscellaneous (any peculiar activity)

- Look Away (from the stimulus while engaged in one of the 4 activities above)

Inter-observer reliability, calculated using Pearson correlation coefficients ( $r$ 's) on a sample of 12 daily sessions, is provided for the cumulative duration of each composite behavioral categories (all p's < 0.001), except Mild Aggression which rarely occurred within the sample.

\section{Data analysis}

One observer first rated all videotapes. Subsequently, a second observer scored samples of the videotapes, distributed over the course of the study. The first observer knew which treatment the animals had received, but the second one did not; inter-observer reliability is provided in Table 1. Before and after presentation of the stimulus, the duration of six different activities defined to be mutually exclusive (Table 1, top) was measured. During stimulus presentation, the duration and frequency of 27 activities (Table 1, bottom), defined to be exhaustive but not mutually exclusive (e.g. Move Toward and Lip Smack can co-occur), were measured. These 27 activities were then grouped into six non-overlapping, composite categories (Mild Aggression, High Aggression, Submission, Defense, Approach, and Other Behaviors).

In the absence of stimuli, individual behavioral scores were expressed as the percentage of time dedicated to each of the six activities during each recorded sample (OFF 1-5), averaged across the four stimuli and three weeks of recording (i.e. all 12 sessions). In the presence of a stimulus, scores were expressed, for each weekly presentation of each stimulus, as the cumulative duration and frequency of the different activities comprising each of the six composite categories. For example, an animal showing Piloerection for $20 \mathrm{sec}$, Eye Aversion for $6 \mathrm{sec}$ and Freezing for $8 \mathrm{sec}$ during a single 20-sec Snake presentation would receive a Defense duration score of $34 \mathrm{sec}$ for that presentation.

Except for High Aggression and Submission, scores were analyzed by parametric analyses of variance (group x OFF segment ANOVAs in absence of stimuli, and group $x$ week ANOVAs in presence of a stimulus) with the Huynh-Feldt correction for factors involving repeated measures, and Tukey tests for pairwise comparisons. Because several animals received a score of zero for the High Aggression and Submission categories, group differences for these measures were evaluated by non-parametric KruskalWallis or Mann-Whitney $U$ tests, as appropriate. For all analyses, the significance threshold was set at $\mathrm{p} \leq 0.05$; however, given the small number of animals per group, all differences at $p \leq 0.10$ are reported. 
Table 2. Behavioral responses of monkeys with rhinal cortical lesions $(R h)$ and unoperated controls ( $N$, Meunier et al., 1999) towards the four stimuli.

\begin{tabular}{|c|c|c|c|c|c|c|c|}
\hline \multicolumn{2}{|l|}{ Duration (sec) } & \multirow{2}{*}{$\begin{array}{l}\text { Human Face } \\
10.7 \pm 3.7 \\
\mathbf{2 . 2} \pm \mathbf{1 . 2} *\end{array}$} & \multirow{2}{*}{$\begin{array}{l}\text { Monkey Head } \\
9.8 \pm 3.2 \\
\mathbf{1 . 9} \pm \mathbf{0 . 8} *\end{array}$} & \multirow{2}{*}{$\begin{array}{l}\text { Snake } \\
\begin{array}{l}2.8 \pm 0.8 \\
6.3 \pm 2.5\end{array}\end{array}$} & \multirow{2}{*}{$\begin{array}{l}\begin{array}{l}\text { Object } \\
\text { (Rewarded) }\end{array} \\
1.8 \pm 0.8 \\
0.7 \pm 0.3\end{array}$} & \multirow{2}{*}{$\begin{array}{l}\begin{array}{l}\text { Object } \\
\text { (Unrewarded) }\end{array} \\
3.08 \pm 1.8 \\
0.5 \pm 0.4\end{array}$} & \multirow{2}{*}{$\begin{array}{l}\begin{array}{l}\text { Average of the } \\
2 \text { 'social' } \\
\text { stimuli }\end{array} \\
10.3 \pm 3.3 \\
\mathbf{2 . 0} \pm \mathbf{0 . 8} *\end{array}$} \\
\hline $\begin{array}{l}\text { MILD } \\
\text { AGGRESSION }\end{array}$ & $\begin{array}{l}\mathrm{N} \\
\mathrm{Rh}\end{array}$ & & & & & & \\
\hline $\begin{array}{l}\text { HIGH } \\
\text { AGGRESSION }\end{array}$ & $\begin{array}{l}\mathrm{N} \\
\mathrm{Rh}\end{array}$ & $\begin{array}{l}16.7 \pm 7.8 \\
15.7 \pm 7.8\end{array}$ & $\begin{array}{l}4.6 \pm 1.8 \\
1.4 \pm 1.1\end{array}$ & $\begin{array}{l}2.5 \pm 1.1 \\
1.1 \pm 1.0\end{array}$ & $\begin{array}{l}2.1 \pm 1.3 \\
0.0 \pm 0.0\end{array}$ & $\begin{array}{l}1.0 \pm 0.4 \\
0.1 \pm 0.1\end{array}$ & $\begin{array}{l}10.7 \pm 3.9 \\
8.5 \pm 3.7\end{array}$ \\
\hline SubMission & $\begin{array}{l}\mathrm{N} \\
\mathrm{Rh}\end{array}$ & $\begin{array}{l}17.1 \pm 4.3 \\
\mathbf{4 . 9} \pm \mathbf{2 . 5} *\end{array}$ & $\begin{array}{l}9.4 \pm 5.0 \\
3.7 \pm 3.7\end{array}$ & $\begin{array}{l}0.5 \pm 0.3 \\
1.2 \pm 0.7\end{array}$ & $\begin{array}{l}0.4 \pm 0.4 \\
0.0 \pm 0.0\end{array}$ & $\begin{array}{l}0.4 \pm 0.4 \\
0.0 \pm 0.0\end{array}$ & $\begin{array}{l}13.3 \pm 3.1 \\
\mathbf{4 . 3} \pm \mathbf{2 . 7} *\end{array}$ \\
\hline Duration (sec) & & Human Face & Monkey Head & Snake & $\begin{array}{l}\text { Object } \\
\text { (Rewarded) }\end{array}$ & $\begin{array}{l}\text { Object } \\
\text { (Unrewarded) }\end{array}$ & $\begin{array}{l}\text { Average of all } \\
\text { stimuli }\end{array}$ \\
\hline DEFENSE & $\begin{array}{l}\mathrm{N} \\
\mathrm{Rh}\end{array}$ & $\begin{array}{l}84.5 \pm 14.3 \\
\mathbf{1 2 1 . 9} \pm \mathbf{1 1 . 1} \\
(\mathrm{Rh}-5: 87.5)\end{array}$ & $\begin{array}{l}87.6 \pm 12.2 \\
\mathbf{1 1 3 . 7} \pm \mathbf{1 0 . 2} \\
(\mathrm{Rh}-5: 48.5)\end{array}$ & $\begin{array}{c}95.4 \pm 8.5 \\
113.4 \pm 7.9 \\
(\mathrm{Rh}-5: 53.8)\end{array}$ & $\begin{array}{l}43.5 \pm 5.0 \\
\mathbf{7 9 . 1} \pm \mathbf{9 . 7} * * \\
(\mathrm{Rh}-5: 1.4)\end{array}$ & $\begin{array}{r}57.2 \pm 7.8 \\
84.9 \pm 16.9 \\
(\mathrm{Rh}-5: 1.8)\end{array}$ & $\begin{array}{l}73.6 \pm 8.1 \\
\mathbf{1 0 5 . 1} \pm \mathbf{3 . 3} * \\
(\mathrm{Rh}-5: 38.6)\end{array}$ \\
\hline $\begin{array}{l}\text { DEFENSE- } \\
\text { Freezing }\end{array}$ & $\begin{array}{l}N \\
R h\end{array}$ & $\begin{array}{l}11.1 \pm 4.6 \\
19.8 \pm 7.6 \\
(R h-5: 0)\end{array}$ & $\begin{array}{l}7.1 \pm 3.7 \\
25.0 \pm 5.4 * \\
(R h-5: 0)\end{array}$ & $\begin{array}{c}27.0 \pm 4.4 \\
33.9 \pm 5.5 \\
(R h-5: 7.1)\end{array}$ & $\begin{array}{l}13.8 \pm 4.4 \\
31.4 \pm 6.6 * \\
(R h-5: 0)\end{array}$ & $\begin{array}{l}17.7 \pm 4.7 \\
30.1 \pm 8.3 \\
(R h-5: 0)\end{array}$ & $\begin{array}{l}15.4 \pm 3.0 \\
27.2 \pm 4.5 * \\
(R h-5: 1.4)\end{array}$ \\
\hline APPROACH & $\begin{array}{l}\mathrm{N} \\
\mathrm{Rh}\end{array}$ & $\begin{array}{l}66.8 \pm 7.2 \\
59.1 \pm 5.1\end{array}$ & $\begin{array}{l}75.4 \pm 8.9 \\
61.5 \pm 9.1\end{array}$ & $\begin{array}{l}62.4 \pm 5.4 \\
62.9 \pm 9.7\end{array}$ & $\begin{array}{l}59.5 \pm 6.8 \\
\mathbf{4 1 . 4} \pm \mathbf{4 . 4}\end{array}$ & $\begin{array}{l}52.5 \pm 8.9 \\
36.1 \pm 7.5\end{array}$ & $\begin{array}{l}63.3 \pm 6.0 \\
53.6 \pm 4.6\end{array}$ \\
\hline $\begin{array}{l}\text { OTHER } \\
\text { BEHAVIORS }\end{array}$ & $\begin{array}{l}\mathrm{N} \\
\mathrm{Rh}\end{array}$ & $\begin{array}{l}2.1 \pm 1.1 \\
2.8 \pm 1.7\end{array}$ & $\begin{array}{l}1.7 \pm 0.7 \\
8.2 \pm \mathbf{2 . 2} *\end{array}$ & $\begin{array}{l}1.2 \pm 0.8 \\
\mathbf{1 1 . 8} \pm \mathbf{5 . 7}\end{array}$ & $\begin{array}{l}39.5 \pm 4.6 \\
32.2 \pm 15.5\end{array}$ & $\begin{array}{l}39.9 \pm 4.7 \\
36.4 \pm 20.9\end{array}$ & $\begin{array}{l}15.9 \pm 1.8 \\
16.1 \pm 7.6\end{array}$ \\
\hline
\end{tabular}

Scores (mean \pm sem) are expressed as the cumulative durations of all activities comprising each of the six composite behavioral categories, summed over the three weeks of recording. For Defense, scores for one specific activity Freezing are given in addition to total scores for that category; for both Defense and Freezing, data from case Rh-5 were excluded from group Rh scores and are presented separately. For Object, scores over the three 20-sec rewarded presentations per session were averaged to allow direct comparison with other scores, which all correspond to a single 20-sec presentation per session. Symbols denote group effects as revealed by parametric ANOVAs (group $x$ week, for each stimulus, and group $x$ stimulus, for average) or, for Submission, by Mann-Whitney U test ( $* * p<0.01, * p<0.05, * 0.06 \leq p \leq 0.10)$.

\section{RESULTS}

Behavior of monkeys with rhinal cortex lesions relative to unoperated controls

Unlike the all-male comparison groups, group $\mathrm{Rh}$ comprised monkeys of both sexes. Hence, we first ran a set of analyses comparing the scores of the three females to those of the three males with rhinal cortex lesions. Gender had no reliable influence on any of the behavioral measures. The six cases with rhinal cortex lesions were therefore pooled into a single group for all subsequent comparisons.

\section{General behavior in the absence of a stimulus}

Analysis of the activities recorded before and after stimulus presentation yielded no significant differences between groups $\mathrm{Rh}$ and N. Like unoperated controls, operated monkeys largely remained motionless, dedicating little time to each of the other five activities (mean \pm sem proportions of time for groups $\mathrm{N}$ and $\mathrm{Rh}$, respectively: Passive, $68.0 \pm 4.2 \%$ vs. $68.8 \pm 10.1 \%$; Move, $19.6 \pm$ $3.1 \%$ vs. $11.7 \pm 3.5 \%$; Manipulate, $2.4 \pm 1.1 \%$ vs. $1.7 \pm 1.0 \%$; Mouth, $1.3 \pm 0.9 \%$ vs. $0.9 \pm 0.6 \%$; Locomotor Stereotypies, $7.4 \pm$ 
$2.4 \%$ vs. $16.5 \pm 10.7 \%$; Self-Directed Activities, $1.3 \pm 0.6 \%$ vs. $0.5 \pm$ $0.5 \%$ ). Three operated animals, however, one male (Rh-3) and two females (Rh-6 and 7), were noticeably more passive (scores, 88-92\%) than any of the unoperated monkeys (maximum score, 78\%), often sitting immobile in a hunched-over posture that was uncommon in controls. Also noteworthy was the unusual amount of stereotypic circling displayed by case Rh-5, a male monkey which reached a score of $60 \%$ for the Locomotor Stereotypies activity compared to a maximum of $16 \%$ in controls. Excessive circling was also present in one female, case $\mathrm{Rh}-2$, but to a lesser magnitude (score, $37 \%$ ), this animal showing peculiar abrupt shifts from periods of rigorous stillness to periods of intense circling.

\section{Behavioral responses to each of the four stimuli}

Scores of groups $\mathrm{Rh}$ and $\mathrm{N}$, summed over the three weeks of recording, are provided in Table 2 for each stimulus and each composite category. Due to its stereotypic circling, case Rh-5 seldom engaged in defensive behaviors; this animal's atypical Defense scores are presented separately in Table 2 and were excluded from the statistical analyses. Note also that, for the Object, data from one case (Rh-4) had to be discarded due to poor video-recording of the stimulus presentations; group $\mathrm{Rh}$ therefore comprises only five animals for this stimulus instead of six for the other three stimuli. Unless explicitly indicated otherwise, the group effects reported in the following paragraphs are differences in duration that persisted over the three weeks of recording.

Human Face. This stimulus was the most effective in triggering aggressive and submissive responses in controls. Animals in group Rh likewise expressed a large amount of High Aggression, although exclusively via head/body lunges and mouth threats, often displayed in a tentative, low-intensity way (i.e. cage shakes, a frequent reaction in controls, never occurred in group Rh). In addition, group Rh exhibited significantly less Mild Aggression (i.e. ears back) and Submission (i.e. lip smacks and grimaces) than controls $[F=4.90$, df $(1,10), p=0.05$, and $U=4, p=0.02$, respectively]. Finally, operated monkeys other than case Rh-5 tended to be more defensive than controls $[F=4.02$, df $(1,9), p=0.08$ ], due primarily to longer move away behaviors [move away scores summed over 3 weeks: N: $39.3 \pm 6.1 \mathrm{sec} v s$ Rh : $55.2 \pm$ $1.8 \mathrm{sec} ; F=5.26$, df $(1,9), p=0.05]$. Note that the Human Face was the only stimulus to evoke defensive behaviors in case Rh-5, rather than stereotypic circling (see Table 2).

Monkey Head. This stimulus elicited the qualitatively most aggressive responses ever observed in controls, that is, striking attacks. Such fiercely antagonistic behaviors were never observed in group $\mathrm{Rh}$, which showed, in addition, a significant reduction in Mild Aggression (viz. ears back) $[F=5.82$, df $(1,10), p=0.04$, and also $F=5.38$, df ( 1 , 10), $p=0.04$, for frequency]. By contrast, defense tended to be increased in all operated animals except case $\mathrm{Rh}-5[F=2.56$, df $(1,9)$, $p=0.14]$, an effect which was most prominent during the third presentation of Monkey Head [week 3; N: $26.2 \pm 5.5 \mathrm{sec} v s \mathrm{Rh}: 44.3 \pm$ $4.2 \mathrm{sec} ; F=6.24$, df $(1,9), p=0.03]$. Specifically, these five operated animals exhibited three times more freezing than the controls [see Table 2; $F=7.87$, df $(1,9), p=0.02]$. Unlike the other operated monkeys, case Rh-5 showed very little Defense, displaying instead bouts of its usual circling routine. Since circling was also present in cases Rh-2 and 6, the Rh group score for Other Behaviors was significantly increased relative to controls $[F=7.46$, df $(1,10), p=$ $0.02]$.
Snake. The controls' hallmark reaction to this aversive stimulus was a high amount of freezing; this reaction was also evident in group $\mathrm{Rh}$, although abnormally low in case Rh-5. Only two group differences emerged in presence of the Snake: a significant Defense enhancement in operated monkeys other than case Rh-5 on week 3 [N: $29.4 \pm 2.8 \mathrm{sec} v s \mathrm{Rh}: 38.8 \pm 2.7 \mathrm{sec} ; F=5.76$, df $(1,9), p=$ $0.04]$ due to increased piloerection and freezing, and a somewhat higher Other Behaviors score for group Rh due to circling in the same three animals as above $[F=3.47$, $\mathrm{df}(1,10), p=0.09$; and also $F=3.63, \mathrm{df}(1,10), p=0.08$, for frequency $]$.

Rewarded Object. Controls showed little Defense during the three rewarded Object presentations, engaging instead in Other Behaviors, in particular manual exploration of the cage and WGTA. This stimulus likewise elicited less fear than the other three stimuli in group Rh (see Table 2). However, except case Rh-5 (which engaged in compulsive circling), operated monkeys remained more defensive than controls $[F=13.62$, df $(1,8), p=0.006]$, showing twice as much freezing [see scores summed over 3 weeks in Table 2; $F=5.31$, df $(1,8), p=0.05]$ and longer eye/head aversions [N: $3.7 \pm 1.2 \mathrm{sec} v s \mathrm{Rh}: 27.2 \pm 5.7 \mathrm{sec} ; F=22.27$, df $(1,8), p=0.002]$. Also, Defense scores in these animals (case Rh-5 excluded) remained high over the three weeks of recording, whereas those in group $\mathrm{N}$ markedly diminished after the first week [group $\mathrm{x}$ week interaction: $F=4.5$, df $(2,16), p=0.03]$. Conversely, Approach responses (viz. move toward, touch, and take reward) tended to be reduced in group $\mathrm{Rh}[F=4.48$, df $(1,9), p=0.06]$, especially on week $3[\mathrm{~N}, 18.0 \pm 1.9 \mathrm{sec} v s \mathrm{Rh}, 11.4 \pm 1.4 \mathrm{sec} ; F=7.56$, df $(1,9)$, $p=0.02]$. As for Other Behaviors, they consisted mostly in circling in group $\mathrm{Rh}$, and only rarely in the manual exploration of the environment seen in controls.

Reward omission effect. This effect was evaluated using parametric one-way ANOVAs to compare, for each group separately, scores averaged over the three rewarded Object presentations per session with scores for the single unrewarded presentation (see Fig. 5). Omission of food reward significantly hindered the controls' positive responses to the Object during the first two weeks of testing, that is, defense was increased and environmental exploration reduced during unrewarded relative to rewarded presentations [Defense: $F=12.83$, df $(1,5), p=$ 0.016; Other Behaviors $F=8.27$, df $(1,5), p=0.035]$. By contrast, none of the responses in group $\mathrm{Rh}$ were reliably affected by reward withdrawal.

\section{Defense scores over all four stimuli}

An analysis of Defense scores averaged over the four stimuli (Table 2) confirmed the overall fear enhancement in group Rh (case Rh-5 excluded) $[F=9.9$, df $(1,9), p=0.012]$. In addition, this fear enhancement was most salient during the sessions in which the controls were the least fearful (the first Human Face presentation, third Monkey Head and Snake presentations, and all three rewarded Object presentations). This was revealed by comparisons of defense scores averaged over the six least fear-inducing sessions with those averaged over the remaining six sessions, using a 2 x 2 ANOVA. Both groups (case Rh-5 excluded) showed defense reduction during less threatening sessions [type of session effect: $F=40.9$, df $(1,9), p<0.001$ ]. However, this reduction was much milder in group Rh than in controls [group $\mathrm{x}$ type of session interaction: $F=6.1$, df $(1,9), p=0.036$ ]. Defense duration scores in controls showed a $37 \%$ drop (from $31.7 \pm$ 3.3 to $20.1 \pm 2.6 \mathrm{sec}$ per presentation), whereas those of the five operated monkeys showed only a $13 \%$ drop (from $38.8 \pm 1.8$ to $33.7 \pm$ $1.0 \mathrm{sec}$ per presentation). 


\section{\begin{tabular}{l|llll} 
Stimulus $O F F$ & $\square \mathrm{N}$ & $\mathbf{R h}$ & $\square \mathrm{A}_{\mathrm{ASP}} \square \mathrm{A}_{\mathrm{IBO}}$
\end{tabular}}

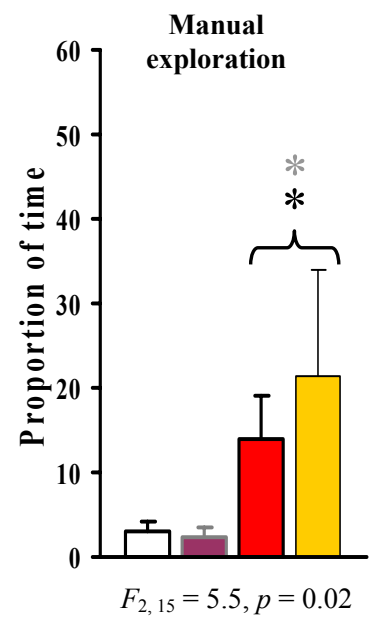

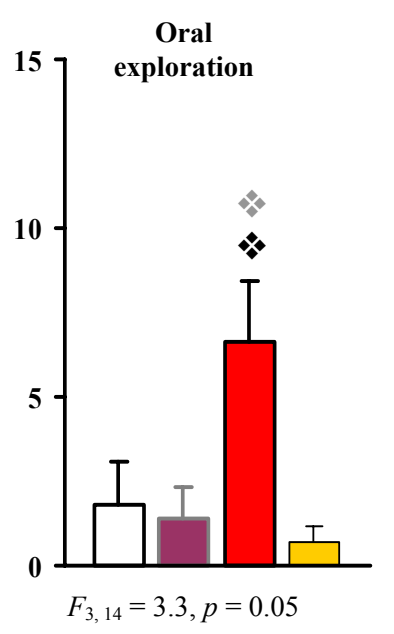

Figure 3. Manual and oral exploration of the transport cage and testing apparatus during the three 1-min segments recorded in the absence of stimuli (mean proportion of time over all 12 weekly sessions \pm sem). $N$, unoperated controls $(n=6) ; R h$, monkeys with rhinal cortex ablations $(n=6) ; A_{A S P}$, monkeys with aspiration removals of the amygdala $(n=3) ; A_{I B O C}$, monkeys with complete neurotoxic lesions of the amygdala $(n=3)$. Parametric ANOVAs were performed for each behavioral activity, symbols denote differences, as revealed by Tukey HSD test, either between operated animals and unoperated controls ( $* p<0.05 ; \quad \leq 0.09$ ), or between one or both of the A groups and the Rh group (* $p<0.05 ; p \leq 0.06$ ). Brackets indicate that groups $A_{A S P}$ and $A_{I B O C}$ did not differ from each other, and were therefore pooled into a single group for the statistical analysis.

Comparison of the changes induced by rhinal cortex versus amygdala lesions

The main differences revealed by direct statistical comparisons of groups $\mathrm{N}, \mathrm{Rh}, \mathrm{A}_{\mathrm{ASP}}$, and $\mathrm{A}_{\mathrm{IBOc}}$ are reported in Figures 3-5. Note that the two A groups, which included only three animals each, were pooled into a single group whenever statistically permissible, in order to reduce the risk of type II error (missing a significant difference) associated with small samples.

\section{Changes in general behavior in the absence of a stimulus}

As illustrated in Fig. 3, amygdalectomized animals showed changes during the three 1-min segments recorded before and after stimulus presentation that were not present in any of the monkeys with rhinal cortex ablations. Namely, all subjects in group $\mathrm{A}_{\mathrm{ASP}}$ displayed an exaggerated tendency to explore the cage and WGTA both manually and orally, and two of the three $A_{I B O c}$ cases showed enhanced manual, though not oral, exploration. Conversely, none of the amygdalectomized subjects presented the compulsive circling characteristic of case Rh-5; excessive Locomotor Stereotypies (39.9\%) did occur in one animal (case $\mathrm{A}_{\mathrm{ASP}}-1$; Meunier et al., 1999), but resulted from a combination of behaviors (viz. rocking, rolling, cage shaking, and idiosyncratic, sudden head tosses with left arm jerks), rather than from a single compulsory activity.

\section{A. HIGH AGGRESSION}

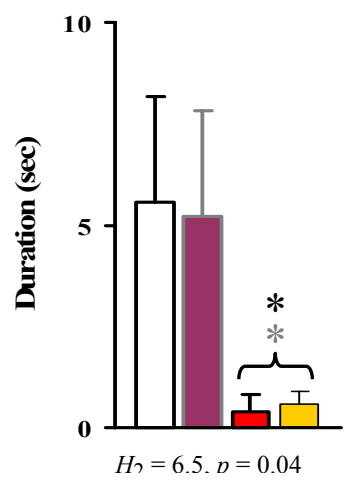

\section{B. SUBMISSION}

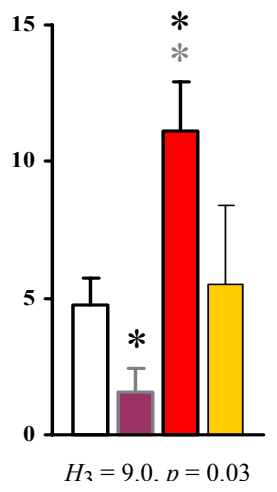

\section{$\square N \square R h \square A_{A S P} \square A_{\text {IBOc }}$}

\section{DEFENSE}

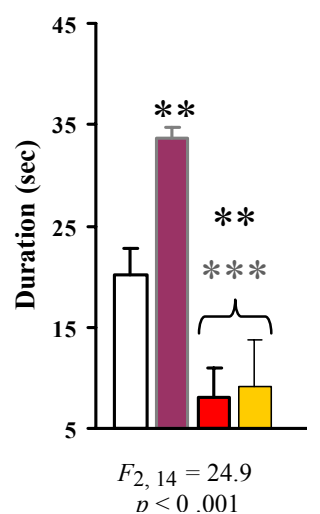

\section{APPROACH}

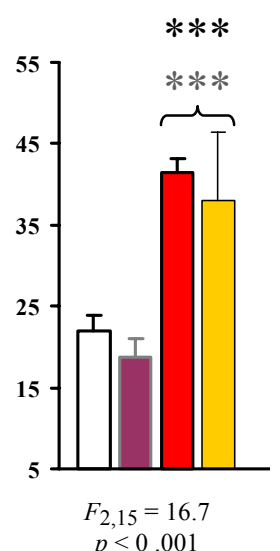

Figure 4. Main differences in the effects of rhinal cortex and amygdala lesions. Scores are mean durations $( \pm \mathrm{sem})$ per 20-sec presentation. A. High Aggression towards Human Face (weeks 1-3). B. Submission towards Human Face (weeks 1-3) and Monkey Head (week 1). C. Defense (case Rh-5 excluded) during the six least fear-inducing weekly sessions (Human Face, week 1; Monkey Head and Snake, week 3; rewarded Object, weeks 13). D. Approach towards the three stimuli presented within the animal's reach (Monkey Head, Snake, and rewarded Object; weeks 1-3). Non-parametric Kruskal-Wallis tests were performed for High Aggression and Submission, and parametric ANOVAs for Defense and Approach. Symbols denote group differences revealed by Mann-Whitney $U$ and Tukey HSD test, respectively, relative to either controls $(* p<0.05 ; * * p<0.01 ; * * * p$ $<0.001)$ or group $R h(* p<0.05$; $* * p<0.01$; $* * * p<$ $0.001)$. Note that because activities within each behavioral category often co-occur, their cumulative duration can exceed $20 \mathrm{sec}$. Other conventions as in Fig. 3. 

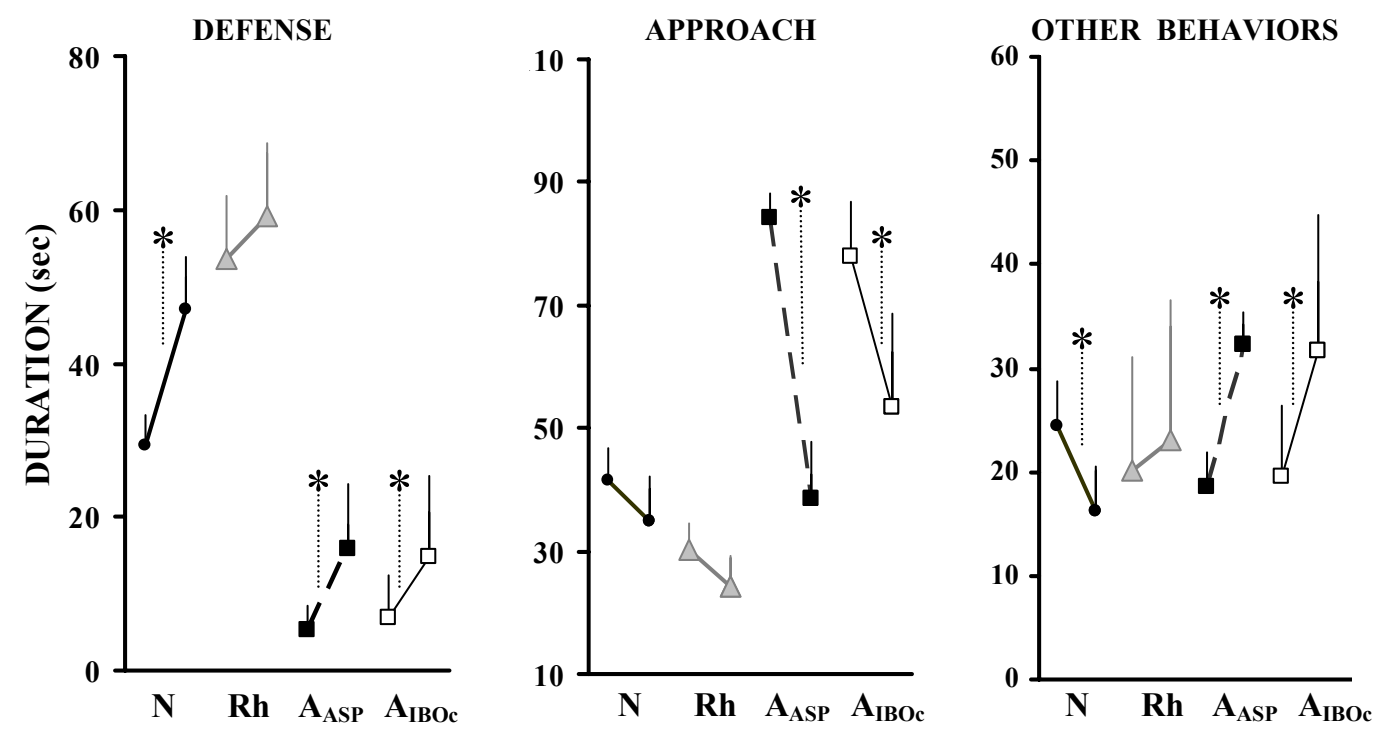

Figure 5. Differences in the effects of rhinal cortex and amygdala lesions on reactions to unexpected omission of food reward during Object presentation. For each group, the first value indicates the average score over the three rewarded Object presentations per session, whereas the second value represents the score during the single, unrewarded Object presentation per session. For each behavioral category, scores are durations (mean \pm sem), summed over the first two weeks of recording. For Defense, scores from case Rh-5 were excluded. Symbols denote significant effects of the reward condition as revealed by within-group, parametric one-way ANOVAs ( $* p<0.05$; the two A groups were pooled into a single group for the statistical analyses). Other conventions as in Fig. 3.

\section{Changes in behavioral responses to the four stimuli}

Aggression. In contrast with the quantitatively normal, but toned down antagonistic repertoire of monkeys with rhinal cortex ablations, aggressive responses in amygdalectomized animals were rare, but of normal intensity when they did occur. Specifically, unlike group $\mathrm{Rh}$, groups $\mathrm{A}_{\mathrm{ASP}}$ and $\mathrm{A}_{\mathrm{IBOc}}$ displayed little or no High Aggression towards Human Face (Fig. 4A), but two monkeys, one from each A group, nonetheless showed fiercely aggressive reactions to Monkey Head (engaging in striking, and even biting attacks), a type of behavior that never occurred in group $\mathrm{Rh}$ (not illustrated).

Submission. Submissive responses also differed between the two groups of operated animals (Fig 4B). Both A groups showed exaggerated submission (including excessive lip smacks and grimaces, but also hindquarter presentations which never occurred in controls) during all three Human Face presentations for group $\mathrm{A}_{\mathrm{ASP}}$, and during the first Monkey Head presentation for group $\mathrm{A}_{\mathrm{IBOc}}$ (see Meunier et al., 1999). Group $\mathrm{Rh}$, on the opposite, was the least submissive group, differing, in particular, markedly from group $\mathrm{A}_{\mathrm{ASP}}$.

Defense and approach responses. The most drastic changes in both groups $\mathrm{A}_{\mathrm{ASP}}$ and $\mathrm{A}_{\mathrm{IBOc}}$ consisted in reduced defense and increased approach reactions. Amygdalectomized animals typically showed no freezing; rather, they touched, mouthed, and smelled the stimuli, both excessively and indiscriminately, whether the stimulus was attractive or aversive. Amygdalectomized monkeys therefore showed markedly increased approach scores for all the stimuli within reach (i.e. all but Human Face; fig 4D). As a corollary, they presented markedly and systematically (i.e. for all 12 sessions) lower defense scores than group Rh (case Rh-5 excluded), the opposite effects of the two types of lesion being most striking over the six least fear-inducing sessions (Fig.4C).

Responses not directed towards the stimuli. These responses (not illustrated), regrouped under the Other Behaviors category, were augmented in both groups $\mathrm{Rh}$ and $\mathrm{A}_{\mathrm{ASP}}$ (though not group $\mathrm{A}_{\text {IBOc; }}$; see Meunier et al., 1999). However, these changes were qualitatively different. Unlike animals in group $\mathrm{Rh}$, which showed increased locomotor stereotypies, monkeys in group $\mathrm{A}_{\mathrm{ASP}}$ displayed enhanced manipulation of the cage and WGTA, consistent with their exaggerated exploration of the stimuli.

Reward omission effect. Unlike group Rh, amygdalectomized monkeys strongly reacted to unexpected withdrawal of food reward during Object presentation (Fig. 5). Specifically, within-group oneway ANOVAs over the first two weeks of testing indicated that, animals in groups $\mathrm{A}_{\mathrm{ASP}}$ and $\mathrm{A}_{\mathrm{IBOc}}$ displayed, like controls, a mild but reliable increase in defense during unrewarded, relative to rewarded Object presentations; in addition, they suppressed their typical excessive investigation of the stimulus (Approach), exploring instead the surrounding cage and WGTA (Other Behaviors). The different reactions of groups $\mathrm{N}, \mathrm{Rh}$, and $\mathrm{A}$ to reward omission were confirmed by $3 \times 2$, lesion $\mathrm{x}$ reward ANOVAs [interaction: Approach, $F=5.79$, df $(2,14), p=0.015$; Other Behaviors, $F=10.6$, df $(2,14), p=0.002]$. 


\section{DISCUSSION}

Changes in responses to emotionally arousing stimuli after rhinal cortex lesions

Monkeys with rhinal cortex ablations presented a set of subtle behavioral alterations that can be summarized as follows. First, all six operated animals were less reactive than controls in presence of the two stimuli with a social component (Human Face and Monkey Head), presenting fewer submissive gestures (lip smacks, and grimaces), and a toned down antagonistic repertoire lacking the most aggressive responses (cage shakes and striking attacks) observed in unoperated animals. Second, approach responses towards a positive item (rewarded Object) tended to be reduced, and the animals failed to react to omission of a presumably expected food reward. Third, five of the six operated monkeys displayed a defense enhancement, which was present for all 4 stimuli and the 3 weeks of recording, but was most salient during the subset of sessions that were the least threatening for controls (i. e. the first Human Face presentation, third Monkey Head and Snake presentations, and all three rewarded Object presentations). The most consistent defense change was a freezing enhancement, but other, more active, defensive activities (viz. move away and eye aversion) were augmented as well. Fourth, whereas, in controls, behaviors not directed towards the stimuli consisted primarily in environmental manipulation that emerged as a corollary of decreased fear in presence of the positive item, in group $\mathrm{Rh}$, these behaviors took mainly the form of stereotypic circling occurring irrespective of the stimulus. Excessive locomotor stereotypies were present in two operated animals, but reached compulsive levels in case Rh-5 (hence the abnormally low defense scores of this animal).

Comments on inter-individual variability and meaning of symptoms in group $\mathbf{R h}$

Inter-individual variability. The heteroge-neity of emotional changes in group $\mathrm{Rh}$ (i.e. the apparently contradictory excessive stereotypies and enhanced freezing) stands in contrast with the remarkable homogeneity of this group in terms of both lesion extent (see Fig. 2) and previous recognition memory impairment (Meunier et al., 1993). This underlines the intrinsic diversity of emotional responsivity which, unlike cognitive performance, relies on a large spectrum of appropriate species-typical responses, and is therefore more sensitive to individual differences. In absence of pre-surgical assessment of the animals' behavior, we can only speculate about the source of the present variability. Early studies in monkeys with conventional amygdalectomy indicate that emotional changes can vary markedly depending on the age, gender, social rank, and personality of the animal, as well as on its specific environment (e.g. Rosvold et al., 1954; Mirsky, 1960; Myers and Swett, 1970; Kling, 1974; Kling and Steklis,1976; Kling and Brothers, 1992). Since age and environment were comparable for all $\mathrm{Rh}$ cases, and gender had no detectable influence, the present variability may reflect the influence of the animal's initial social rank and temperament on the behavioral outcome of the lesion. In this perspective, excessive stereotypies and enhanced defense may simply represent different individual expressions of the same disorder (e.g. an abnormal withdrawal from the environment). Future studies assessing the impact of rhinal damage in naturalistic, social situations, and after thorough preoperative evaluation of each individual's behavior, are needed to test this hypothesis.
Meaning of specific symptoms. An impedi-ment inherent in studying emotions in non-verbal-species is the difficulty to establish an unequivocal link between a quantifiable overt behavior and the subjective experience or affect that might accompany it. Hence, pending additional investigations, caution is required in interpreting the symptoms following rhinal damage. For example, freezing, i.e. durable ( $\geq 3 \mathrm{sec})$ immobility in presence of a stimulus, appears as a reliable indicator of stimulus-driven fear in unoperated animals: it was triggered primarily by the Snake in controls, and its average duration was unrelated to the immobility (i.e. Passive) scores recorded in periods without stimulus (Pearson $r=0.40, p$ : n.s.). By contrast, in group $\mathrm{Rh}$, freezing occurred with all stimuli, including the rewarded Object, and was strongly correlated with the passivity recorded in the absence of stimulus $(r=0.98, p=0.001)$. Thus, although the increase in other, more active, defensive behaviors (viz. move away and eye aversion) pleads for enhanced stimulusdriven fear reactions in group $\mathrm{Rh}$, the increase in freezing might result, at least in part, from a more general, internally-driven hyporeactivity. Likewise, the excessive stereotypies of case $\mathrm{Rh} 5$ were evident both with and without the stimuli, suggesting a chronic change rather than altered phasic responses to specific situations. More studies are now required to ascertain the meaning of these symptoms. Meanwhile, it is of interest to note that all the behaviors present in group Rh during periods without stimulus, namely the paucity of movement, lack of environment exploration, and hunched-over postures of some cases, and the excessive locomotor stereotypies of others, are symptoms that have been considered as indicative of a depressive state in monkeys (Goosen 1981; Suomi, 1982). Although highly speculative, a chronic shift towards an internal state akin to depression would also explain the toned-down aggression, and attenuated approach and submission observed in all $\mathrm{Rh}$ cases in presence of the stimuli.

Influence of rhinal cortex damage associated with amygdala lesions

Notwithstanding the above limitations, the present study provides the first direct comparison of the emotional changes following rhinal cortex versus amygdala lesions in monkeys. Taken together with earlier findings (Meunier et al., 1999), the results indicate that 1) complete cell loss in the amygdala slightly invading the entorhinal, though not the perirhinal cortex $\left(\mathrm{A}_{\mathrm{IBOc}}\right)$, yields reduced fear, excessive manipulation, hyperorality, hypo-aggression and exaggerated submissiveness, 2) all symptoms, but fear reduction, are exacer-bated after amygdala aspiration $\left(\mathrm{A}_{\mathrm{ASP}}\right)$ including not only mild direct damage to entorhinal cortex but also extensive indirect damage to the entorhinal, perirhinal, TG, and TE cortical areas, and 3) rhinal cortex ablations alone (Rh) yield none of the above symptoms, but tend instead to attenuate submission and approach, and to heighten defense or stereotypies.

The lack of similarity between the Rh and the two A groups indicates that ablations restricted to the entorhinal and perirhinal areas are insufficient to yield Klüver-Bucy-like symptoms in monkeys. Hence, the exacerbated symptoms following amygdala aspiration cannot result from a straightforward additive effect of the attendant interruption of rhinal cortex fibers. Rather, the different, and sometimes opposite, changes observed in group $\mathrm{Rh}$ raise the possibility that rhinal cortex does make a contribution to normal regulation of emotional responses in monkeys, but one which is distinct from that of the amygdala. 
Rhinal Cortex Lesions and Emotional Responses

\section{Rhinal cortex and the emotional significance of sensory stimuli}

The possibility of a rhinal cortex involvement in emotions has heretofore received little consideration. Rather, a decade of intense studies (see e.g. Murray \& Bussey, 1999 for review) has now established that, unlike the amygdala, the rhinal cortex has important perceptual and mnemonic functions, congruent with its dual position as the end and first multimodal station of the ventral visual ("what") pathway, and gateway to the hippocampus (Suzuki, 1996). However, the rhinal cortex also possesses intimate connections with both the amygdala and orbital cortex (Suzuki, 1996). It is thus critically placed to integrate emotional and perceptual/mnemonic processes, perhaps by storing the emotional significance of prior experience. Some emerging evidence supports this conjecture.

Cells in perirhinal cortex, like neurons in neighboring visual area $\mathrm{TE}$, are responsive to complex visual items, including social stimuli such as conspecific faces (Brothers \& Ring, 1993). Nevertheless, neural responses reflecting the association of the sensory features of a visual cue with its behavioral meaning, are present in perirhinal cortex, but not in visual area TE (Liu and Richmond, 2000; see also Liu et al., 2000). Likewise, perirhinal cells can form, through experience, representations linking physically unrelated objects that have a meaningful connection (Erickson \& Desimone, 1999; Erickson et al., 2000). Similar associative properties exist in area TE neurons, but are dependent upon feedback from rhinal cortex (Higuchi \& Miyashita, 1996). Thus, unlike area TE, perirhinal cortex present neural properties reflecting not only the sensory features of stimuli, but also their affective significance. In line with this idea, perirhinal cortex appears to play a prominent role in the acquisition of conditioned fear responses to olfactory stimuli in rats (Otto et al., 2000), and the human parahippocampal region was found activated (together with the amygdala) during visual processing of threatening words relative to neutral words (Isenberg et al., 1999), and also (together with the orbital cortex) during listening of unpleasant, dissonant relative to pleasant, consonant music (Blood et al., 1999).

\section{Amygdala and the regulation of emotional responses}

Although amygdala functions remain a matter of debate, recent studies using neurotoxic lesions in monkeys outline a more circumscribed syndrome than that classically described after temporal lobectomies or conventional amygdalectomies. Selective lesions, like more extensive ones, can have variable effects; a staring unfamiliar human, for example, can elicit exaggerated submission (Meunier et al., 1999), increased aggression (Machado \& Bachevalier, 2000), or no change at all (Kalin et al., 2001). Nevertheless, the most common disorders reported to date in animals observed alone or in dyads consist in a reduction of fear, including snake fear, excessive and indiscriminate exploration of objects, and overly affiliative behaviors towards human or conspecific stimuli (Meunier et al., 1999; Emery et al., 2001; Kalin et al., 2001). Thus, monkeys with selective amygdala damage appear to often ignore the potential threat inherent in unfamiliar inanimate and social stimuli, following instead their spontaneous exploratory and contact-seeking tendencies. Accordingly, electrical activity in the monkey normal amygdala reflects the degree of ambiguity of the socio-emotional context, the greatest activity being recorded in situations of high uncertainty, such as a conspecific behaving in an unpredictable manner or a setting associated with unpredictable shocks (Kling et al., 1987; Lloyd \& Kling, 1991). Data in monkeys therefore fit well with a current model positing the amygdala as part of a "continuous vigilance system, one that is preferentially involved in ambiguous learning situations of biological relevance" (Whalen, 1998).

\section{Amygdala and rhinal cortex interaction in emotions: a speculation}

Unknown objects or conspecifics are ambiguous insofar as, based on prior experience, they can predict many different outcomes, from pleasant to life-endangering. As a result, normal monkeys interact cautiously with an unfamiliar stimulus until they learn its specific outcome (see e.g. Emery et al., 2001). We propose that the rhinal cortex and amygdala interact in this normal adaptation to affective stimuli, the rhinal cortex contributing to provide the emotional knowledge acquired in related past experience that is necessary for the amygdala to detect ambiguous stimuli. As a result, monkeys with amygdala damage would neglect the multiple possible meanings of new stimuli; whereas monkeys with rhinal cortex would engage in abnormal withdrawal from all stimuli. Although distinct, these deficits would, when cumulated, converge to amplify Klüver-Bucy-like symptoms. Indeed, poor storage of past experience meaning can only aggravate amygdalectomized animals' tendency to neglect the ambiguity of incoming stimuli, and further hamper the function of related structures such as the orbital cortex. In this view, extra-damage to rhinal cortex, whether direct or indirect, could contribute, albeit indirectly, to the exacerbated symptoms following amygdala aspiration. This proposal is offered in the most tentative way as a working hypothesis for future studies.

We wish to thank Elisabeth A. Murray for help performing the surgeries and evaluating the extent of the lesions, as well as for her support and helpful discussions during the course of the study, Mortimer Mishkin for his advice and support, Rick Duntz for help in collecting behavioral data, Zachary D. Torry for scoring behavioral data as a second observer, and Fadila Hadj-Bouziane and Christopher J. Machado for helpful comments on the manuscript. This study was supported by NIMH-IRP, NATO International Scientific Exchange Programs to MM and JB, NIMH-58846 and NICHD35471 to JB, and the CNRS to MM.

Akert K, Gruesen R.A., Woolsey CN, Meyer DR (1961) Klüver-Bucy syndrome in monkeys with neocortical ablations of temporal lobe. Brain 84:480-498.

Aggleton JP and Passingham RE (1981) Syndrome produced by lesions of the amygdala in monkeys (Macaca mulatta). J Comp Physiol Psychol 95:961-977.

Baxter MG, Saunders RC, Murray EA. (1998) Aspiration lesions of the amygdala interrupt connections between prefrontal cortex and temporal cortex in rhesus monkeys. Soc Neurosci Abstr 24:1905.

Blood AJ, Zatorre RJ, Bermudez P, Evan AC (1999) Emotional responses to pleasant and unpleasant music correlate with activity in paralimbic brain regions. Nature Neurosci. 2:382-387.

Brothers L, Ring B (1993) Mesial temporal neurons in the macaque monkey with responses selective for aspects of social stimuli. Behav. Brain Res. 57:53-61.

Emery NJ and Amaral DG (1999) The role of the amygdala in primate social cognition. In: Cognitive Neuroscience of Emotion (Lane RD, Nadel L, eds), pp156-191. Oxford: Oxford UP.

Emery NJ, Capitanio JP, Mason WA, Machado CJ, Mendoza SP, Amaral DG (2001) The effects of bilateral lesions of the amygdala on dyadic social interactions in rhesus monkeys (Macaca mulatta). Behav Neurosci, in press. 
Erickson CA, Desimone R (1999) Responses of macaque perirhinal neurons during and after visual stimulus association learning. J Neurosci 19:1040416.

Erickson CA, Jagadeesh B, Desimone R (2000) Clustering of perirhinal neurons with similar properties following visual experience in adult monkeys. Nat Neurosci 3:1143-48.

Franzen, E.A. \& Myers, R.E. (1973) Neural control of social behavior: prefrontal and anterior temporal cortex. Neuropsychologia, 11, 141-157.

Goosen C (1981) Abnormal behavior patterns in rhesus monkeys: symptoms of mental disease? Biol Psychiatry 16:697-716.

Goulet S, Doré FY, Murray EA (1998) Aspiration lesions of the amygdala disrupt the rhinal corticothalamic projection system in rhesus monkeys. Exp Brain Res 199:131-140.

Higuchi SI, Miyashita Y (1996) Formation of mnemonic neuronal responses to visual paired associates in inferotemporal cortex is impaired by perirhinal and entorhinal lesions. Proc Natl Acad Sci USA 93: 739-743.

Horel JA, Misantone LJ (1974) The Klüver-Bucy syndrome produced by partial isolation of the temporal lobe. Exp Neurol 42:585-594.

Horel JA, Keating EG, Misantone LJ (1975) Partial Klüver-Bucy syndrome produced by destroying temporal neocortex or amygdala. Brain Res. 94:347-359.

Isenberg N, Silbersweig D, Engelien A, Emmerich S, Malavade K, Beattie B, Leon AC, Stern E (1999) Linguistic threat activates the human amygdala. Proc Natl Acad Sci USA 96:10456-59.

Iwai E, Nishio T, Yamagucchi K (1986) Neuropsychological basis of a K-B sign in Klüver-Bucy syndrome produced following total removal of inferotemporal cortex of macaque monkeys. In: Emotion: Neural and Chemical Control (Oomura Y, ed), pp299-311. Tokyo:Japan Scientific Society Press.

Kalin NH, Shelton SE, Davidson RJ, Kelley AE (2001) The primate amygdala mediates acute fear but not the behavioral and physiological components of anxious temperament. J Neurosci 21:2067-74.

Kling AS (1974). Differential effects of amygdalectomy in male and female nonhuman primates. Arch Sexual Behav 3:129-134.

Kling AS, Brothers L (1992) The amygdala and social behavior. In: The Amygdala: Neurobiological aspects of emotion, memory, and mental dysfunction (Aggleton JP, ed), pp.353-377. New York: Wiley-Liss.

Kling AS, Steklis HD (1976) A neural substrate for affiliative behavior in non-human primates. Brain Behav Evol, 13:216-238.

Kling AS, Lloyd RL, Perryman KM (1987) Slow wave changes in amygdala to visual, auditory, and social stimuli following lesions of the inferior temporal cortex in squirrel monkey (Saimiri sciureus). Behav Neural Biol 47: 54-72.

KlingAS, Tachiki K, Lloyd R (1993) Neurochemical correlates of the Klüver-Bucy syndrome by in vivo microdyalisis in monkey. Behav Brain Res 56:161-170.

Klüver H and Bucy P (1939) Preliminary analysis of functioning of the temporal lobes in monkeys. Arch. Neurol. Psychiat. 42:979-1000.

Liu Z, Richmond BJ (2000) Response differences in monkey TE and perirhinal cortex: stimulus association related to reward schedules. J Neurophysiol 83:1677-92.

Liu Z, Murray EA, Richmond BJ (2000) Learning motivational significance of visual cues for reward schedules requires rhinal cortex. Nat Neurosci 3:1307-15.

Lloyd RL, Kling AS (1991) Delta activity from amygdala in squirrel monkeys (Saimiri sciureus): Influence of social and environmental context. Behav Neurosci 105: 223-229.

Machado CJ, Bachevalier J (2000) Selective lesions to the amygdala, hippocampus or orbital frontal cortex alter reactivity to a human intruder in monkeys. Soc Neurosci Abstr 26:
Málková L, Mishkin M, Suomi SJ, Bachevalier J (1997) Socioemotional behavior in adult rhesus monkeys after early versus late lesions of the medial temporal lobe. Ann NY Acad Sci 807:538-540.

Meunier M, Bachevalier J, Murray EA, Merjanian PM, Richardson R (1991) Effects of rhinal cortical or limbic lesions on fear reactions in rhesus monkeys. Soc Neurosci Abstr 17:337.

Meunier M, Murray EA, Bachevalier J, Mishkin M (1993) Effects on visual recognition of combined and separate ablations of the entorhinal and perirhinal cortex in rhesus monkeys. J Neurosci 13: 5418-5432.

Meunier M, Hadfield W, Bachevalier J, Murray EA (1996) Effects of rhinal cortex lesions combined with hippocampectomy on visual recognition memory in rhesus monkey. J Neurophysiol 75: 1190-1205.

Meunier M, Bachevalier J, Murray EA, Málková L, Mishkin M (1999) Effects of aspiration $v s$ neurotoxic lesions of the amygdala on emotional responses in monkeys. Eur J Neurosci 11:4403-4418.

Meyer DR (1972) Some features of the dorsolateral frontal and inferotemporal syndromes in monkeys. Acta Neurobiol Exp (Warszawa) 32:235-260.

Mineka S, Cook M (1988) Social learning and the acquisition of snake fear in monkeys. In: Social Learning: Psychosocial and Biological Perspectives (Zentall T, Galef B, eds), pp. 51-73. Hillsdale, NJ: Erlbaum.

Mirsky, A. F. (1960). Studies of the effects of brain lesions on social behaviors in Macaca mulatta: Methodological and theoretical considerations. Annals of the New York Academy of Science, 85, 78594.

Murray EA (1996) What have ablation studies told us about the neural substrates of stimulus memory? Semin Neurosci 5:10-20.

Murray EA, Bussey TJ (1999) Perceptual-mnemonic functions of the perirhinal cortex. Trends Cogn Sci 3:142-151.

Murray EA, Gaffan EA, Flint RW Jr (1996) Anterior rhinal cortex and amygdala: dissociation of their contributions to memory and food preference in rhesus monkeys. Behav Neurosci 110:30-42.

Myers RE, Swett C (1970) Social behavior deficits of free-ranging monkeys after anterior temporal cortex removal: a preliminary report. Brain Res 18:551-556.

Otto T, Cousens G, Herzog C (2000) Behavioral and neuropsychological foundations of olfactory fear conditioning. Behav Brain Res 110:11928.

Raleigh MJ, Steklis HD (1981) Effects of orbitofrontal and temporal neocortical lesions on the affiliative behavior of Vervet monkeys (Cercopithecus aethiops sabaeus). Exp Neurol 73:378-389.

Rosvold HE, Mirsky AF, Pribram KH (1954) Influence of amygdalectomy on social behavior in monkeys. J Comp Physiol Psychol 47:173-178.

Suomi SJ (1982) Abnormal behavior and primate models of psychopathology. In: Primate Behavior (XXX ed), pp 171-215. New York: Academic Press.

Suzuki WA (1996). The anatomy, physiology and functions of the perirhinal cortex. Curr Op Neurobiol 6:179-186.

Weiskrantz L (1956) Behavioral changes associated with ablation of the amygdaloid complex in monkeys. J Comp Physiol Psychol 49:381-391.

Whalen, P.J. (1998) Fear, vigilance, and ambiguity: Initial neuroimaging studies of the human amygdala. Curr Dir Psychol Sci 7:177-188.

Zola-Morgan S, Squire LR, Alvarez-Royo P, Clower RP (1991) Independence of memory functions and emotional behavior: separate contributions of the hippocampal formation and the amygdala. Hippocampus 1:207-220. 